\title{
ALLIANCE PORTFOLIO DIVERSITY, RADICAL AND \\ INCREMENTAL INNOVATION: THE MODERATING ROLE OF TECHNOLOGY MANAGEMENT
}

\author{
L.A.G. Oerlemans ${ }^{\mathrm{a}}$, b, J. Knoben ${ }^{\mathrm{c}}$, M.W. Pretorius ${ }^{\mathrm{b}}$ \\ ${ }^{a}$ Department of Organization Studies \& Center for Innovation Research, Tilburg \\ University, The Netherlands \\ ${ }^{\mathrm{b}}$ Graduate School of Technology Management, Department of Engineering and \\ Technology Management, University of Pretoria, South Africa \\ ${ }^{\mathrm{c}}$ Institute for Management Research, Radboud University, Nijmegen, The Netherlands
}

\begin{abstract}
In this paper we test whether the use of a set of technology management tools (TM-tools), a specification of alliance portfolio capability, influences the relationship between alliance portfolio diversity and a firm's innovation outcomes. With this model, we add to the theoretical literature on the performance effects of alliance portfolio diversity and specific contingencies allowing to appropriate benefits from this diversity. Based on a sample of South African firms, we first confirm the inverted U-shaped relation between alliance portfolio diversity and a firm's innovation outcomes found by earlier research. We also show that the shape of this inverted-U differs for incremental and radical innovation outcomes. Subsequently, we test the moderating effect of the use of TM-tools on this relationship, for which find a strong positive moderating effect. In particular, for firms intensively using TM-tools, the negative effect of high levels of alliance portfolio diversity on innovation outcomes turns into a positive effect. This suggests that the use of formal technology management practices is beneficial to manage highly diverse alliance portfolios.
\end{abstract}

KEYWORDS: ALLIANCE PORTFOLIO; PORTFOLIO DIVERSITY; INNOVATION; TECHNOLOGY MANAGEMENT 


\section{Introduction}

One of the latest sprouts of the alliance literature focuses on portfolios of alliances (Wassmer, 2010), which are commonly defined as sets of alliances, thus concerning ego-networks including firms' direct inter-organizational ties with alters. It is shown that the prevalence of alliance portfolios is increasing over time (Lavie, 2009) and that the characteristics of portfolios, such as their diversity, impact a firm's innovation outcomes above and beyond what can be expected by the presence of the sum of individual alliances (Faems et al., 2005; Phelps, 2010).

Alliance portfolio diversity is a multi-dimensional construct and can be generally defined as the distribution of differences in partners' characteristics. Previous research has shown that many of the dimensions of alliance portfolio diversity significantly affect various firms' outcomes. Yamakawa et al. (2011), for instance, find that a high proportion of exploitative ties in an alliance portfolio, which is a form of functional diversity, has a negative return on assets effect. Jiang et al. (2010) report that alliance portfolios with greater organizational and functional diversity and lower governance diversity were associated with higher net profit, whereas partner diversity has a non-linear relationship with this specific firm outcome. Lavie and Miller (2008) present a sigmoid relationship between alliance portfolio diversity in terms of internationalization (including geographical diversity of partners) and financial performance of firms.

This study focuses on the relationship between a specific dimension of alliance portfolio diversity, namely, alliance portfolio partner diversity (hereafter APPD), and firms' innovation outcomes. The latter is defined as the proportion of sales from products or services that were technologically improved versions of existing ones (incremental) or were technologically new to the 
market (radical). The alliances taken into account are technological collaborations with a wide range of external partners (e.g., buyers, suppliers, universities, research labs) possessing different types of knowledge, which defines the concept of APPD. In these alliances, partner firms actively work together on the development of technologically new or strongly improved products, processes and services.

Recent empirical studies on the relationship between APPD and innovation and other knowledge related outcomes converge to a similar conclusion; there is an inverted U-shaped relationship between the two (Duysters and Lokshin, 2011; Laursen and Salter, 2006; Vasudeva and Anand, 2011). An exception is a study by Wuyts and Dutta (forthcoming), who report that alliance portfolio diversity and superior innovation performance are U-shaped related, which is according to them probably due to the benefits of both a focus and a diversity strategy in the particular industry under study (pharmaceuticals). These predominantly focus on innovation outcomes as a single construct, whereas there is reason to assume that the effects of alliance partner diversity on incremental and radical innovation outcomes differ, for example because incremental and radical innovation may require different type, depth and variety of knowledge. The configuration of alliance partner portfolios may thus be more suitable for one of the innovation types, but not for both. In this study, we argue that the performance impact from alliance portfolio partner diversity tends to be higher for incremental innovations in comparison to more radical innovations due to the fact the former innovations are more technological proximate to existing products, predictable and less risky (Yamakawa et al., 2011), which implies that it is relatively easier to be successful in the market with this type of innovations. By addressing these performance differentials we fill a gap in the alliance portfolio literature.

The most important gap in the literature regarding APDD and innovative outcomes, however, is the lack of insights into whether managers can influence this relation through conscious and targeted managerial effort. It has been recognized that not all organizations benefit to the same extent from alliance portfolio partner diversity, resulting in several scholars calling for a contingency perspective (Schilke and Goerzen, 2010; Wassmer, 2010). In this regard, a recent literature review on alliance management (Kale and Singh, 2009) concluded that a vast majority of scholarly work has focused on 
the management of single inter-organizational relationships. The same study observed that alliance portfolios bring new managerial challenges (Hoffman, 2007; Hoffman, 2005). First, an organization needs to assess to what extent the composition of its alliance portfolio is in fit with its strategic needs. Second, while building its portfolio, it has to deal with competition that might grow between individual partners in the portfolio. Third, it has to ensure that the synergetic benefits that accrue from complementary alliances in its portfolio are actually reaped by the firm (Kale and Singh, 2009: 57). In particular, managerial action becomes relevant when an organization collaborates on technological matters with a diverse set of alliance partners. In the light of the above, this study puts forward the notion that the negative performance effects of high diversity levels can be positively influenced by focused managerial effort in the form of technology management. Technology management is defined as the capability to stimulate the effective use of technical knowledge and skills to develop new products and processes, the improvement of existing technology, and the generation of new knowledge and skills, and is a specification of what Sarkar et al. (2009) label as alliance portfolio coordination because it helps in identifying, selecting and combining relevant technologies in the hands of a diverse set of external actors, with whom the focal firm has technological collaborations (Phaal et al., 2001).

Therefore, we put forward the following research question: What is the effect of alliance portfolio partner diversity on a firm's innovation outcomes, and what is the effect of the use of TMtools on this relationship? Answering this research question will contribute to the literature in several distinct ways. First and foremost, we contribute to alliance portfolio (management) literature by showing that the negative effects of high levels of APPD on innovation outcomes can be counteracted by conscious and focused managerial efforts. Preceding studies predominantly focus on the development of capabilities and management functions aiming for the improvement of the functioning of individual alliances, but say relatively little about which managerial interventions innovating firms put in place to coordinate and profit from externally acquired knowledge and information acquired from a portfolio of inter-organizational ties. Second, we propose, and empirically find, differing effects of APPD on radical and incremental innovation. Third, we contribute to increasing the generalizability of empirical findings in alliance portfolio diversity literature by studying the 
performance effects of alliance portfolios of firms in a non-western context, that is, in South Africa for a wide range of industries and size classes.

\section{Theory and hypotheses}

\subsection{Alliance portfolio partner diversity and the innovation outcomes of firms}

There is a small but growing literature on the innovation outcome implications of firms' linkage in diverse alliance partner portfolios. The different partners in these portfolios possess different types of knowledge. Universities and research labs, for example, give access to fundamental knowledge and the possibility of conducting high quality research (Laursen and Salter, 2004; von Raesfeld et al., 2012). Suppliers possess knowledge related to production processes and input characteristics that could lead to process innovation, cost reduction or product innovation (Sobrero and Roberts, 2002), whereas buyers can be sources of new product ideas (Hernandez-Espallardo et al., 2011; von Hippel, 2007). Collaboration with competitors gives access to industry-specific knowledge and a possibility of sharing, for example, research facilities (Gnyawali and Park, 2011; Kim and Higgins, 2007) and consultants and private research organizations can be valuable sources, for example because they offer engineering capabilities or marketing knowledge helping in commercializing innovations (Tether and Tajar, 2008; Toedtling et al., 2009).

The curvilinear relationship between alliance partner diversity and firm innovation found in previous research (Duysters and Lokshin, 2011; Laursen and Salter, 2006) has been explained by two partly overlapping theories - the extended resource-based view (Lavie, 2006) and organizational economics (e.g. Belderbos et al., 2006). At low levels of APPD, firms are connected to the same kind of partners possessing similar resources. Consequently they have limited access to complementary assets and new knowledge (Faems et al., 2005) and they have limited possibilities of profiting from synergies across a set of dyads. Furthermore, a focal actor has limited possibilities for learning from feedback (Ruef, 2002). As a result, firms' innovation outcomes tend to be relatively low. As the level of APPD increases, risks of knowledge and information redundancies diminish, whereas a wider 
variety of complementary assets can be accessed. A more diverse set of alliances also act as a sounding board for new innovative ideas of the focal actor and can lead to a decrease of intra-alliance competition costs (Belderbos et al., 2006). At moderate levels of APPD, firms profit the most from diversity of inflowing knowledge, and at the same time they are able to deal with the diversity of the portfolio (Bruyaka and Durand, 2012). As diversity levels further increase, costs of the portfolio may overcome the benefits (Bapuji et al., 2011; Chen et al., 2011). There are several reasons why this may be the case. Higher diversity levels imply the inflow of (too) many ideas, often emerging at the wrong time, and getting too little attention, all of this resulting in an information overflow problem (Koput, 1997). Furthermore, collaborating with a highly diverse set of actors substantially increases the costs of coordination, monitoring and communication, and the probability of opportunism, for example resulting in unintended knowledge spillovers (Combs and Ketchen, 1999).

In sum, as argued in the literature, low alliance diversity levels will be associated with low innovation outcomes; also that increased alliance diversity levels will improve outcomes, but very high alliance diversity levels confront firms with such high costs and negative effects that innovation outcomes are negatively influenced. Hence, our first hypothesis reads:

\section{Hypothesis 1. There is an inverted U-shaped relationship between a firm's level of alliance portfolio partner diversity and its level of innovation outcomes.}

There is reason to believe, however, that not all types of innovation outcomes are equally affected by APPD. We argue that more diverse alliance portfolios are especially conducive to incremental types of innovative performance because incremental innovation implies that dominant designs already have emerged, which implies that de facto technological standards are present in the marketplace. Many firms devote resources to develop competencies that align with such dominant designs (Utterback and Abernathy, 1975). In such contexts, firms focus on fine-tuning products in a step-by-step way, which is easily inspired by a diverse set of external actors (Laursen and Salter, 2006). Radical innovation, on the contrary, involves the development or application of new technologies. This has two implications for APPD. First, radical innovation performance is the result of the introduction and acceptance in the market of a firm's new products and services that extends its competencies significantly (Voss et al., 
2008). The generation of such products and services preceding this performance asks for novel types of knowledge often not available in the innovating firm and only possessed by specific specialized external actors, like for example specialized universities or lead-users (Lettl, 2007). In other words, the creation of more radical innovations requires emphasis on access to scarce capabilities and expertise, the possession of which is unequally distributed by residing in the hands of only a very few partners or of partners of a specific type. Therefore, focal firms collaborate with a less diverse set of external partners (Laursen and Salter, 2006). Second, the development of radical innovations is more unpredictable and sporadic. Most firms will experience difficulties in adapting their knowledge creation and management practices to meet the needs of such projects, or lack the capacity to efficiently absorb the inflowing knowledge (Feller et al., 2007). As a result, only maintaining a set of less diverse ties and focusing all attention on those ties is likely to be a beneficial strategy for the generation of radical innovation.

Existing empirical research provides support for this line of reasoning. Riggs and Von Hippel (1994) showed that a majority of innovations in the scientific instruments industry came from lead users, whereas radical innovations in the biotechnology sector are mainly triggered by university research (Hall and Bagchi-Sen, 2007). Moreover, an empirical study in the telecommunication industry by Feller et al. (2007) showed that incremental innovators collaborated with a wider and more internationalized range of external actors compared to radical innovators, whereas radical innovators that did collaborate partnered with actors who possessed less similar and complementary knowledge resources. We therefore pose the following hypothesis:

\section{Hypothesis 2a: The level of alliance portfolio partner diversity that maximizes innovation outcomes is higher for incremental innovations as compared to radical innovations.}

Furthermore, the magnitude of the short-term outcome implications of incremental and radical innovations is likely to differ as well. The inflow of more diverse knowledge brings not only novelty to the firm, but also an increasing probability of failure and lower adoption rates in the market. Put differently, the short-term performance impact for the focal firm from more incremental innovations tends to be higher in comparison to more radical innovations due to the fact the former innovations are 
more proximate and predictable, and less risky (Yamakawa et al., 2011). Due to these characteristics, the features of incremental innovations can be more easily recognized and appreciated by external users generating a higher probability of short-term sales, whereas more radical innovations are more alien to users and take more time to get diffused. Therefore, we pose the following hypothesis: Hypothesis 2b: For the alliance portfolio partner diversity level resulting in the maximum level of innovation outcomes, the outcome level is lower for radical innovations as compared to incremental innovations.

It is relevant to note that for reasons of simplicity, it is assumed for hypotheses $2 a$ and $2 b$ that the shape of the inverted U-shaped curve does not change.

\subsection{The Moderating Effect of Technology Management}

Innovation and knowledge transfer processes in which diverse external partners are involved are, however, difficult organizational activities due to the costs, complexities and uncertainties related to technological innovation in general, and to the complexity of assessing diverse knowledge flows across organizational boundaries (Lin et al., 2012). It is therefore unlikely that the capabilities to assess inflows of knowledge acquired from a selected set of diverse actors are evenly distributed across firms. In particular, the technology management tools used by firms to identify and select technologies held by external partners can be argued to moderate the relationship between APPD and innovation outcomes.

In this study, the use of technology management tools in the context of multiple collaborations is regarded as a dimension of alliance portfolio capability. Following Kale and Singh (2009: 57), a distinction can be made between alliance capability (aiming at managing single alliances) and alliance portfolio capability. The latter concept refers to a firm's ability to manage its set of alliances as a portfolio and comprises the development and implementation of a portfolio strategy, the monitoring and coordination of the alliance portfolio, and the institutionalization of multi-alliance management (Hoffman, 2005). We focus on a specific set of alliance portfolio activities relevant in the context of 
technological collaboration and stressed by several scholars (Duysters et al., 1999; Parise and Casher, 2003). In particular, we focus on managerial tools enabling capturing, sharing and leveraging information and knowledge across an alliance portfolio. Technology management (TM) tools are managerial routines suitable for these purposes.

Technology management can be defined as the capability to stimulate the effective use of technical knowledge and skills to develop new products and processes, the improvement of existing technology, and the generation of new knowledge and skills (Jin and von Zedtwitz, 2008). Cetindamar et al. (2009) have suggested that technology management comprises five generic activities: identification of technologies which are or may be of relevance to the organization; selection of technologies that should be supported by the organization; acquisition and assimilation of selected technologies; exploitation of technologies, and; protection of knowledge and expertise. Especially, identification (e.g. technology and market scanning) and selection (technology forecasting and monitoring) are relevant activities as they facilitate the understanding of the inflow of diverse knowledge through technological collaborations, and they enable firms to benefit from complementarities across and between internal and external knowledge sources (Cassiman and Veugelers, 2006). Typical identification and selection activities conducted are internal technology audits (analyzing the current technological capabilities of the firm), competitor analysis (identification of the current competitive position of the organization), and external technology audit (getting an overview and understanding of future technological options and their implications) (Ford, 1988; Frishammar and Hörte, 2005; Levin and Barnard, 2008). These three groups of TM activities are discussed in more detail below.

An internal technology audit is a set of related analyses conducted to identify the strengths and weaknesses of the current internal technological assets of an organization. It encompasses assessments not only of product and process technologies, but also of service and marketing technologies of the organization. It comprises technology and innovation audits, core competence assessment, intellectual property audits, and innovation project portfolio analysis. The application of these internal auditing activities boils down to an evaluation of internal strengths and weaknesses of the tangible and 
intangible technological assets (Phaal et al., 2006). Organizations performing these activities are more aware of the strengths of their own technological knowledge bases.

A second set of relevant TM activities relates to the identification of the current competitive position of the organization. Any firm needs to sell its products and/or services. Knowledge about the market and the behaviour and preferences of costumers is therefore indispensable, especially when putting new products on the market. Market analysis is therefore an important TM activity as well. Complementary to market analysis is competitor analysis, which involves collecting, analyzing and acting on information and knowledge about competitors and the competitive environment (Khalil, 2000). This analysis produces information not only on the overall market structure, but also on the position of an organization relative to competitors. Industry analysis refers to an investigation of the position of an organization in the value chain. By evaluating the strengths and weaknesses of its current position in the value chain, an organization can determine to what extent the bargaining power of suppliers and distributors is affecting its competitive advantage. Conducting market, competitor, and industry analysis increases the knowledge and awareness of an organization in its current competitive position. Packed with this knowledge and awareness, an organization is able to better position itself relative to other actors in its business environment (Khalil, 2000).

Besides these activities, it is also relevant to get an overview and understanding of future technological options and their implications, in other words to perform an external technology audit. Such overviews can be used to gain a better understanding of the threats and opportunities that probably impact on established technologies, products and markets. As technology is causing major changes in society and organizations, determining future technological options is vital. Organizations can conduct several activities to investigate future technology strategy options. The literature (Khalil, 2000) suggests several activities aimed at creating images of the technological future such as technology monitoring and scanning, technology forecasting and foresighting, and competitive technological intelligence (Hidalgo and Albors, 2008).

We propose that the use of TM-tools will moderate the effect of APPD on innovation outcomes of firms. We argued in hypothesis one that the overall relationship between APPD and 
innovation outcomes was curvilinear. The question remains, however, how does this relationship differ when the use of TM-tools varies?

At low levels of TM-tool use, the relationship between alliance partner diversity and innovation outcomes is affected only marginally, because the low diversity levels of the acquired external knowledge do not pose major processing problems, and efforts to manage the alliance portfolio can be limited. A higher use of TM-tools allows firms to better perceive the availability and quality of external knowledge resources held by their alliance partners and, due to the link with internal technology monitoring, enables firms to make a better judgment of the potential and synergetic value of these resources in the context of the technology base of their own organization. This becomes especially impactful once diversity levels exceed a certain (moderate) threshold level at which processing problems with inflowing knowledge and information relevant for innovation would emerge without the use of TM-tools. TM activities are the most valuable when the diversity of a firm's alliance portfolio increases to the highest levels, because in that case by nature very different knowledge and information coming from a very diverse set of alliance partners has to be recognized, valued and processed (Sarkar et al., 2009). Moreover, utilizing more TM-tools allows firms to exploit complementarities between internal and external technology bases more fully, which is an especially valuable activity in the context of high levels of APPD as well. In other words, utilizing many TMtools allows firms to benefit from high levels of APPD by facilitating the recognition of valuable external resources across their alliances and combining those with internal resources resulting in better and more novel products and, ultimately, in higher levels of innovation performance. The above line of reasoning leads to hypothesis $3 \mathrm{a}$ :

H3a: The relationship between alliance portfolio partner diversity and a firm's innovation outcomes is positively and significantly moderated by the use of technology management tools when APPD is higher.

On the basis of the characteristics of radical as compared to incremental innovations, it is reasonable to argue that the moderating of TM-tool use will differ between the two types of innovation. Given that incremental innovations are improved versions of existing products or services, utilizing a 
relatively low number of TM-tools, primarily geared towards competitive positioning and auditing the internally available knowledge, should be sufficient to make the most out of even highly diverse alliance portfolios. Radical innovations, on the other hand, are products and services that are new to the market and therefore by definition unfamiliar to the firm. Generating such innovations requires state-of-the-art knowledge and the ability to turn that knowledge into commercially viable products and services. In order to filter the relevant knowledge from a highly diverse alliance portfolio, the firm needs to have knowledge of its competitive position and the strengths and weaknesses of its internal technological assets, but of core importance is the ability to apply external technology audits. The latter TM-tool set gives firms with radical innovation a better overview and understanding of future technological options, and their implications, enabling them to determine a course in uncertain technological fields.

In a nutshell, whereas relatively low levels of TM-tool use are already sufficient to counteract the negative effects of high levels of APPD for incremental innovation, high levels of TM-tool use are required to do the same for radical innovation. This line of reasoning leads to hypothesis $3 \mathrm{~b}$ :

H3b: The positive moderation effect of the use of technology management tools is stronger for radical as compared to incremental innovations.

\section{Empirical application}

\subsection{Data}

The theoretical ideas put forward in the previous sections will be tested by utilizing data of the South African Innovation Survey 2001 (SAIS2001). The SAIS2001 questionnaire was based on the European Community Innovation Survey, but adapted to the South African context. The population of firms in the survey consisted of all South African firms in manufacturing, services, and wholesale with 10 or more employees that conducted economic activities in the period 1998-2000. As a sampling frame the Reedbase Kompass database was used. This database contains 16,931 South African firms with a known number of employees. In SAIS 2001 stratified sampling was used as the sampling 
technique. The population of South African firms was divided into three different size classes (strata). Taking the number of employees as an indicator of the size of a firm, the following three strata were distinguished: Stratum 1: firms with 11 to 20 employees (768 sampled firms); Stratum 2: 21 to 50 employees (2,606 sampled firms); and Stratum 3: more than 50 employees (3,665 sampled firms). The way the strata were chosen is on the one hand the result of the firm size structure of the South African economy: a small number of very large organizations and a very high number of small and very small (micro) companies. On the other hand, to enhance comparability with the European CIS studies, it was decided to include all of the larger firms (stratum 3) in the sample.

The survey was mailed to, in total, 7,039 firms of which $8.8 \%(\mathrm{~N}=617)$ returned the survey. This is a low figure, but not uncommon for organizational level questionnaire research, which often yields relatively low response rates (Baruch, 1999). Nevertheless, the fact that a large group of firms did not respond raises the question whether the data might suffer from sample bias, or not. Therefore, a telephonic non-response analysis among 462 firms was conducted. Questions were asked about specific reasons for not responding, and about some key firm characteristics, for example R\&D activity. The response to the non-response survey was very high (90\%). Amongst others, nonresponding firms were asked whether they had technological innovations in the period 1998-2000 and with what frequency they conducted R\&D. As the same information was gathered in the written questionnaire, a comparison of the response and the non-response groups could be made. The results of this comparison can be found in Table 1. As can be derived from this table, the comparison between respondents and non-respondents revealed no statistically significant differences.

Insert table 1 here

To further substantiate the representativeness of the data, population estimates of our survey have been compared with estimates produced by Statistics South Africa. All estimates based on the SAISdatabase were very close to the population estimates. In particular, our population estimate of the annual growth of employment in the period $2000-2003$ is $1.2 \%$. This is exactly the same figure as the estimate provided by Statistics South Africa. Based on the non-response analysis and the comparison 
of population estimates, the response group can be considered as representative of the total population of South African firms, which implies that the data is likely to be unbiased despite the relatively low response rate.

As noted in the above, the SAIS 2000 database contains information on 617 firms. In this research, a subset of 419 firms will be analyzed. This subset has been created by selecting only firms that reported conducting innovation activities. This selection has been made because many of the questions, for example about technological alliances and technology management, were only asked of firms that indicated conducting at least some innovation activities. Moreover, this selection is completely in line with the theoretical mechanisms we aim to research, since these all assume that firms are trying to get access to resources that help them to be, or to become, innovative. It is important to emphasize, however, that not all of these firms were necessarily engaged in alliances, nor were these firms necessarily successful in putting new products and/or services on the market. Therefore, our sample demarcation does not imply any selection on either the dependent or the main independent variable.

\subsection{Measurements}

\subsubsection{Innovation outcomes}

To operationalize a firm's innovation outcomes, we used self-reported measures of innovativeness that were developed for the Community Innovation Survey (CIS) (Brouwer and Kleinknecht, 1996). First, managers were asked whether their firms had introduced new or improved products or services in the previous two years (1998-2000). A two year period was chosen to avoid bias resulting from measuring a one-off or incidental innovation. For firms that indicated having done so, their innovation outcomes were determined by asking what percentage of the firm's turnover in 2000 was generated by: (a) products or services that were technologically improved versions of existing ones or (b) were technologically new to the market (identical to: Laursen and Salter, 2006). 
This measurement is in line with generally accepted definitions of incremental and radical innovation, and prior research has shown that this perception-based measure of innovation outcomes is highly reliable and correlates highly with other (objective) measures of innovation outcomes (Hagedoorn and Cloodt, 2003). Typical examples of radical innovations developed by South African firms are the cryoprobe, a device that is cooled through the Joule-Thompson effect of gas expansion and used for cataract surgery, and the MultiCam, which is the world's first sensor to detect high voltage transmission failures. Examples of incremental South African innovations are dry cooling technology, which is used at power generation plants for significant water saving and innovation in deep-mining technology.

\subsubsection{Alliance portfolio partner diversity}

The SAIS 2001 database contains data about the types of alliance partners a firm has, and whether these alliances are with domestic and/or international partners. Respondents were asked the following question: "Innovation in partnership is working actively and together with other partners on the development of technologically new or strongly improved products, services, and processes. Most of the times, but not always, costs and revenues are shared in these partnerships. Between 1998-2000, did your firm participate in such partnerships with organizations located in South Africalforeign countries?" It is important to note that this question refers to alliances maintained in the period 19982000 , whereas the measures of innovation outcomes pertain to the year 2000 only. This lag has been introduced to capture the fact that it takes some time before the resources obtained through alliances find their way into innovative products and/or services. Doing so reduces the problems of endogeneity and reversed causality, and thereby strengthens the internal validity of the study.

If firms indicated that they maintained such partnerships, they were subsequently asked to indicate with which type of South African and foreign partners they did so. The question took the form of a two bulleted list, one for South African partnerships and one for international partnerships, where respondents could check the relevant partner types. Specifically, eight types were distinguished in the questionnaire: 1) buyers, 2) suppliers, 3) competitors, 4) consultants, 5) research institutes, 6) 
universities, 7) own business group, and 8) an open category labeled 'other'. Given that our conceptualization of alliance portfolio diversity focuses on differences in partner types, and not on differences in geographical scope, we combined the two lists of partner types into a single list in which a firm is considered to have a partner of a certain type if it maintains a South African and/or international partnership with that type of partner. APPD is subsequently calculated by dividing the number of different types of partners maintained by the firm by the maximum possible amount of different partners (in this case eight) and squaring the result of this division. It is important to note that this measure is not indicating alliance portfolio size. More diverse portfolios purely signal that a more diverse set of external actors possessing diverse knowledge sources are part of the ego network of the firm.

The result of this simple calculation is a diversity score with a value between 0 (least diverse) and 1 (highest diversity) that has a convex relationship with the number of different partners maintained by the firm. We chose this specification because it corresponds to Blau's index of heterogeneity which has been used frequently in the alliance literature to measure portfolio diversity (Duysters and Lokshin, 2011). Other specifications, such as linear and concave ones, can be found in the literature as well (e.g. Laursen and Salter, 2006). Therefore, the effects of different specifications of the diversity function are discussed in the robustness checks section of this paper.

\subsubsection{Use of TM-tools}

The SAIS 2001 database contains information about the types of technology management tools (TMtools) that an innovating firm uses. In line with the theoretical definition of the concept, three groups of TM tools were distinguished: firm internal, external (market), and technology monitoring TMtools. With regard to internal TM-tools, firms are asked whether they utilize: 1) technological audits of the own organization, 2) core competence assessment of the own organization, 3) intellectual property audits, and 4) project portfolio management. External, market oriented TM-tools are 5) competitor analysis, 6) industry analysis, and 7) market analysis. Finally, firms are asked whether they utilize 8) 
technology monitoring, 9) technology forecasting, and 10) competitive technological intelligence as measures of the utilization of TM-tools that monitor technology.

In total, ten different TM-tools are distinguished. The variable 'use of TM-tools' is a count variable that captures the number of different TM-tools that a firm uses, and it therefore varies between 0 (no TM-tools) and 10 (maximum TM-tools).

\subsubsection{Control variables}

Several control variables were included in the analyses. First, we control for the use of codified external knowledge sources by the firms, because these can constitute another source of external knowledge (besides alliances), which could influence innovation outcomes on the one hand, and substitute for the use of alliances on the other (Oerlemans and Pretorius, 2006). To construct this variable we asked questions about the extent to which firms judged the use of patents, electronic databases, and professional literature to be important for their innovation activities (on a scale of 0 to

3). The answers to these three questions were condensed into a single measure with the help of factor analysis, which revealed that the three questions indeed reflect a single concept, use of codified knowledge sources $(\alpha=0.761)$.

Moreover, a firm's internal capacity to generate and process knowledge is also likely to impact on its innovation outcomes (Cohen and Levinthal, 1989). Therefore, the R\&D intensity of a firm is controlled for by including a measure that captures the percentage of personnel of a firm involved in R\&D activities. Firms were asked to give an estimate of their R\&D effort in man-years in a certain year. The variable $R \& D$ intensity was calculated by dividing the latter number by the total number of employees in the same year, and it takes values between $0 \%$ and $100 \%$. We did not use more traditional measures of R\&D involvement due to the fact that South African firms (as with firms in many transition economies) have a very low propensity to patent. For example, according to the World Intellectual Property Organization (www.wipo.int), in the period 2005-2009 about only 400 patents were filed annually by all South African companies together. This number is far too low to be a reliable firm-level indicator of $R \& D$ effort. 
Another control variable that we included is a count variable for the number of different types of bottlenecks to innovation that a firm has experienced over the last two years. Ten potential bottlenecks are distinguished ranging from economic risks to knowledge shortages and institutional rigidities, and firms were asked to indicate whether they experience one or more of the bottlenecks mentioned. However, no single firm indicates that they experienced all 10 types of bottlenecks; this resulted in a variable with a range from 0 to 9 . This variable aims to capture the hampering factors to the firm innovation activities, potentially pushing a firm to seek cooperation partners to overcome existing bottlenecks (Duysters and Lokshin, 2011).

Moreover, we control for firm size by including in the analysis the natural logarithm of the amount of full-time employees that a firm has. Several studies have found that inter-organizational network activity and innovation outcomes are size-dependent. Size indicates resource endowment amongst other factors, and we argue that larger size enables firms to maintain a larger set of alliances and is conducive to outcomes.

We include dummy variables for exporting firms and for foreign owned (versus SouthAfrican) firms. Regarding exports, firms were asked to indicate whether they had generated sales from products and services sold outside South Africa. Including export as a control variable is informed by the notion that exports might serve as a means to getting access to novel information and technological knowledge not available in the domestic market (Kafouros et al., 2008). Whether a firm was owned by a foreign partner was probed by the question whether the head office of the firm was located in South Africa. Foreign ownership was included as a control variable because firms in emerging economies often benefit highly from technological knowledge available from their international headquarters and research labs ((Isobe et al., 2000). We also included a count variable that captures the number of twodigit NACE-sectors in which a firm is active, to represent its level of diversification, which might influence both the firm's alliance portfolio diversity and its innovation outcomes (Miller, 2004). Finally, we control for differences between sectors by including dummy variables for different Pavittsectors. The last two variables were determined on the basis of their NACE classifications, which were indicated in the sampling frame. We also estimated models with firm level sales and employment growth as control variables. Because these variables were: a) insignificant in all models, and b) not 
available for all firms in our sample, we only report and discuss the models without these control variables.

It is important to note that we cannot directly control for alliance portfolio size as the data is not included in the dataset we utilize. However, we have included several other control variables in the dataset that have been shown by earlier research to correlate highly with alliance portfolio size, but not with alliance portfolio diversity. For example, we control for firm size, which earlier research has shown to correlate 0.53 with alliance portfolio size (Jiang et al., 2010). Other variables that we control for, that have been shown to correlate with alliance portfolio size, are the knowledge base of the company (Yamakawa et al., 2011) and the degree of diversification of the firm (Jiang et al., 2010). So even though we cannot directly control for the size of the alliance portfolio of the firm, we believe our other control variables adequately pick up this effect.

\subsection{Descriptive Statistics}

Descriptive statistics for all of these variables can be found in tables 2 and 3, and bivariate correlations are reported in Table 4. Table 2 reveals that the average percentage of turnover from incremental innovations is about $17 \%$ whereas for radical innovations this is roughly $7 \%$. In our sample, 137 firms realize no turnover whatsoever from innovations, whereas 134 firms generate turnover from incremental but not from radical innovations. Only three firms generate turnover from radical but not from incremental innovations and, finally, 145 firms generate turnover from both types of innovations. Furthermore, Table 2 reveals that there are firms without internal R\&D that are still able to generate sales from innovation.

With regard to APPD, the firms in our dataset are spread out across the entire scale. The average APPD is 0.17 , which corresponds to a little over three types of alliances (out of the possible eight). With regard to the use of TM-tools, the firms in our dataset again cover the full scale (0 to 10$)$, with the average firm utilizing a little below three different TM-tools. Table 3 breaks down how the use of different types of TM-tools (i.e. competitive positioning, internal technology audits and external technology audits) is distributed across low, medium and high TM-tool users. It is important that firms 
that use few TM-tools predominantly use competitive positioning tools such as market analyses or competitor analyses. There are some low TM-tool users that have internal technology audit tools in their activities but almost none that use external technology audit tools. Medium TM-tool users almost always use competitive positioning tools and predominantly add internal technology audit tools, such as internal knowledge audits, to their activities. High TM-tool users complement their activities with external technology audit tools, such as technology forecasting. As such, there seems to be an ordering in the different types of TM-tools, that has competitive positioning tools as the basis and external technology audit tools as the pinnacle.

Table 4 shows that all bivariate correlations are relatively low, as are the Variance Inflation Factors presented in Table 2. Two correlation coefficients ask for some attention. The first one regards the positive correlation (.52) between APPD and the number of TM-tools used, which on the one hand indicates that our moderating variable might have statistical relevance, whereas on the other the size of the coefficient does not indicate a multicollinearity problem. The second correlation is the one between APPD and the use of codified knowledge sources (0.58). It indicates that firms with a more diverse set of technology alliances are also using this external knowledge source. It shows the relevance of including the latter variable as a control variable. Based on these results, we conclude that there are no problems of multicollinearity in our dataset.

Insert table 2 here

Insert table 3 here

\subsection{Methods}


For both measures of innovation outcomes that we use as dependent variables, the score lies between $0 \%$ and $100 \%$ by definition. The most appropriate method to analyze such left and right censored data is a Tobit analysis. Moreover, the data for both measures of innovation outcomes is also highly skewed to the left. As a result, the assumption of a normal distribution of the residuals that is made in a Tobit analysis is violated (significance of Shapiro-Wilk test of 0.000 for both dependent variables). In order to deal with this problem we have log-transformed the dependent variable (Papalia and Di Iorio, 2001).

In order to test the moderating effects of TM-tools on the relationship between APPD and innovation outcomes, several interaction variables have to be entered into the models. In order to prevent any multicollinearity problems between the main effects and the interaction effects, we have mean centered the variables before calculating the interaction terms. Moreover, we performed several robustness checks to make sure multicollinearity does not influence our results (see robustness checks section). To prevent any biases from heteroskedasticity problems we utilized the Huber/White robust specification of standard errors.

Earlier research has shown that there is bi-directional relation between interorganizational alliances and firm performance. Firms with more alliances perform better, and better performing firms attract more alliance partners. Even though this simultaneous causality has, to our knowledge, not been proven to hold for APPD in particular, endogeneity might be an issue in our data. Besides introducing the time lag between the measurement of innovation outcomes and APPD we also estimated instrumental variables regressions. Given the fact that we utilize survey data, the choice of instrumental variables is rather limited. We used (in all possible different combinations) the number of bottlenecks to innovation, whether the firm received innovation subsidies from the government or not (dummy) and whether the firm exports or not (dummy). The instruments are marginally relevant (a first stage F-statistic of 9.08; Bascle, 2008)), but Hausman specification tests indicate that the efficient model also yields consistent results. This conclusion is corroborated by $\mathrm{Wu}-\mathrm{Hausman}$ and Durbin-WuHausman tests (Bascle, 2008) which do not reject the null-hypothesis that the regressor (APPD) is exogenous. Therefore, the results of the Tobit regression that we report are unlikely to be biased as a result of simultaneous causality problems. 


\section{Results}

The results of the estimations of the Tobit models are presented in Table 5. For both dependent variables, that is, two types of innovation outcomes, three different models have been estimated. First, models with only the control variables were estimated (models 1 and 4). These models establish a baseline against which the other models can be evaluated. Second, the APPD variables (both linear and squared) were added to the model (models 2 and 5). Finally, the moderating effect of the use of TM-tools has been introduced into the models (models 3 and 6).

Insert table 5 here

Both of the baseline models (models 1 and 4) are highly significant and have relatively high levels of explanatory power for firm-level models (respectively $36 \%$ and 19\%). The findings for both models are highly consistent. The use of codified external knowledge sources and the level of internal R\&D are positively associated with a firm's levels of both incremental and radical innovation outcomes. The same holds for the number of innovation bottlenecks that firms encounter, which is also positively associated with the firm's innovation outcomes. On the one hand, this reflects the notion that the fewer innovation activities a firm exhibits, the less likely the chance that it will encounter any problems. So encountering bottlenecks is a sign of conducting relatively high levels of innovation activities. On the other hand, experiencing more bottlenecks invokes more external search attempts. The main difference between the two models is that foreign owned firms have higher levels of incremental innovation outcomes as compared to domestic firms, whereas no such difference is found for radical innovation outcomes.

Subsequently, we added the APPD variables (models 2 and 5). This addition leads to a highly significant improvement of the models in terms of log-likelihood reduction, estimation accuracy (represented by sigma (i.e. the estimated standard error of the residuals)), and of variance explained. The results regarding the control variables remain largely unchanged. 
The coefficients for the APPD variables (linear and squared) are both highly significant and have the signs that correspond to the predicted inverted U-shape. To get a clear insight into the exact shape of the relation between APPD and a firm's innovation outcomes, we plotted this relationship for both types if innovation outcomes in Figure 1. To enhance comparability between the two effects for incremental and radical innovation outcomes, the effects have been standardized.

\section{Insert Figure 1 here}

This figure clearly shows an inverted U-shape relationship for both types of innovation outcomes. It could be the case, however, that the model predicts the down-sloping part of the curve, but that this part is not statistically significant. To investigate this issue, we estimate models where the APPD variables are replaced with a set of dummies. ${ }^{3}$ For both radical and incremental innovation outcomes, the benchmark is set for APPD values around the tipping point. Dummies are created for firms without any alliances, for firms with some alliances but below the tipping point, and for firms with more diverse alliance portfolios than the tipping point. The results of these analyses show that for both types of innovation, the downward sloping part of the curve is significant. In sum, hypothesis 1 is confirmed for both incremental and radical innovation.

Figure 1 also shows that the optimal level of APPD differs between the types of innovation outcomes. The optimal level is lower for radical innovation outcomes $(0.50)$ than for incremental innovation outcomes (0.60). Given our non-linear specification of APPD, these numbers correspond to maintaining 5.6 (radical innovation) respectively 6.2 (incremental innovation) different types of partners. These relative levels of diversity are similar to those reported by Duysters and Lokshin (2011) and Laursen and Salter (2006). Based on these findings hypothesis 2a is confirmed.

With regard to the maximum levels of innovation outcomes for radical versus incremental innovation, we find that the estimated maximums do differ in the predicted way. The maximum impact of APPD is higher for incremental as compared to radical innovation. Moreover, analyses regarding the uncertainty surrounding the predicted maximum reveals that this difference is statistically highly significant $(\mathrm{p}<0.0 .00)$. So our results provide strong support for hypothesis $2 \mathrm{~b}$. 
Finally, the interaction terms between APPD and the use of TM-tools were entered into the model (models 3 and 6), again resulting in a significant improvement of the models (see Table 5). The pseudo R-square of the incremental innovation model rises to over $68 \%$, whereas that of the radical innovation model climbs up to a respectable $29 \%$. Again, the log-likelihood reductions are highly significant and the estimations become more accurate (reflected in the lower sigma).

The newly added moderating effects are statistically highly significant and have the signs that are in correspondence with those predicted in hypothesis $3 \mathrm{a}$ and $3 \mathrm{~b}$. However, it is hard to interpret the coefficients directly, which is why the relation between APPD and a firm's innovation outcomes has been plotted in Figure 2a and $2 b$.

Insert Figure $2 \mathrm{a}$ and $2 \mathrm{~b}$ here

What emerges from Figure $2 a$ and $2 b$ is largely in line with the predicted effects. Especially in the higher ranges of APPD, utilizing TM-tools is highly beneficial for firms. The negative effect of high levels of APPD is not only dampened, but even turns into a strong positive effect. On the lower part of the portfolio diversity domain, the differences are less pronounced or even insignificant. One could interpret this as evidence that firms do not need TM-tools to deal with low to moderate levels of APPD. Overall, these findings provide strong support for hypothesis $3 \mathrm{a}$, which is therefore confirmed. With regard to the differences in the moderation effect between incremental and radical findings, the findings are less pronounced. The switching point at which firms really start benefitting from high levels of TM-tool use lies at 7 for incremental innovation and 9 for radical innovation. However, given the uncertainty margins surrounding those predictions, we cannot conclude that the two switching points are statistically significant. The same holds for the predicted levels of innovativeness for high TM-tool using firms which are higher for radical as compared to incremental innovation, but the difference is again not pronounced enough to be statistically significant. So even though are findings tentatively point in the direction predicted in hypothesis $3 \mathrm{~b}$, we reject this hypothesis. 


\subsection{Robustness Checks}

Several robustness checks have been performed to assess the sensitivity of the results to changes in model specifications.

\subsubsection{Different specification of alliance portfolio partner diversity}

In our analyses, we have adopted a convex relation between the number of different types of alliances a firm maintained and its APPD. Even though this is the dominant specification that is used in the literature, different specifications can be made as well. In order to test the sensitivity of the results to changes in this specification, we also applied a linear specification and a concave specification of the relation between the number of alliance types a firm has and its level of APPD. Regressing these different specifications of APPD on innovation outcomes leads to almost identical results as compared to the ones obtained with the convex specification of alliance portfolio. This clearly indicates that our findings are robust to such changes in the specification of this independent variable.

\subsubsection{Different specifications of dependent variable}

Besides the log-transformed percentage of sales derived from innovative products and services, several different specifications of the dependent variable have been used to test the robustness of the results. We estimated the Tobit models on the non-log-transformed percentage of sales from innovative products and services data and on a binary variable that simply indicated whether the firm had any innovative sales at all (identical to: Duysters and Lokshin, 2011). The results were highly robust to these changes in specification.

\subsubsection{Estimation on random sub-samples}


Models with moderation effects are sensitive to multicollinearity and heteroskedasticity issues. In order to minimize these problems we have utilized robust standard errors and mean centered all variables before calculating the interaction terms. Nevertheless, it is sometimes argued that the estimated coefficients of, in particular, the interaction effects can be very sensitive to mutations in the underlying dataset (Echambadi and Hess, 2007). In order to assess this sensitivity we estimated the model for both incremental and radical innovation outcomes on 20 randomly drawn sub-samples of our dataset (as suggested by: Echambadi and Hess, 2007). Each sub-sample contained approximately $50 \%$ of the observations of the full dataset. For each of these 20 sub-samples, results were obtained that are virtually identical to those reported in Table 5. Therefore, we conclude that our results are highly robust to changes in the underlying dataset and are not biased due to multicollinearity or heteroskedasticity issues.

\section{Discussion and conclusions}

From the findings presented in Section 4, we derive several contributions. First, we contribute to the alliance portfolio management literature by showing that the use of TM-tools, focusing on the identification and selection of external technological knowledge, strongly impacts on the relationship between APPD and a firm's innovation outcomes. Previous alliance portfolio management literature has shown that it is beneficial for organizations to have an alliance function and/or a dedicated alliance manager (Draulans et al., 2003; Kale et al., 2002; Lichtenthaler and Lichtenthaler, 2004) but basically black-boxed the focused actions that alliance managers or functions undertake. Our study opens up this black box and point at the importance of organized, specific, and directed managerial action and the formalization of technology management for benefiting from a high level of alliance partner portfolio diversity. Our findings are in line with results reported in the latest best practice study by the Product Development \& Management Association, in which it is reported that firms with the highest innovation outcomes use a high number of formal tools simultaneously (Barczak et al., 2009). The finding is also somewhat counter-intuitive, however, as scholars argue that high levels of 
formalization are negatively related to technological creativity, innovation and knowledge production (Lee and Choi, 2003), which signals that high levels of formalization are detrimental to innovation. It might be that the object of formalization plays a crucial role in this regard. For example, formalization directed at outcomes might have negative effects, whereas formalization of behavioral aspects (e.g. identification and selection) might improve or speed up the creation of innovations (Brown and Eisenhardt, 1997).

Second, on a more general level, our study also shows that agency of organizations is highly important in inter-organizational settings. We show that the effect of the composition of a firm's alliance portfolio on its performance is not set in stone but can be altered by conscious managerial actions. We hereby contribute to the inter-organizational network literature which often ignores the fact that firms differ in the actions that they take and the capabilities that they have, and that they might therefore benefit differently from being in comparable network environments. By showing that organizational action, in the form of engaging in TM-tool use, can turn a negative effect of APPD into a positive effect, we have clearly shown that agency is at the core of understanding the benefits firms derive from their networks.

Third, this study adds to the generalizability of the relation between alliance portfolio diversity and innovation outcomes. Our findings show that also in a non-Western, across-industry and nonhigh-tech context there is strong evidence for the hypothesized inverted U-shaped relation with differing effects for incremental and radical innovation outcomes. As such, our findings show that the theoretical arguments underlying this hypothesis are also valid outside of the contexts in which they had so far been tested.

Moreover, two important managerial implications can be derived from this study. Essentially our study informs managers whether they should deploy TM-tools and, if they should, what specific types of managerial actions are most beneficial to undertake. With regard to the former, firms should carefully monitor the partner diversity of their alliance portfolio in order to make informed decisions regarding the deployment of TM-tools. As long as a firm maintains relatively low levels of APPD, the deployment of TM-tools does not add much to a firm's innovative performance. As such, firms at 
those levels of APPD should refrain from investing heavily in the deployment of TM-tools as those investments are unlikely to lead to substantial improvement in innovative outcomes. Only at a relatively high level of alliance portfolio partner diversity does the use of TM-tools really make a difference.

With regard to the latter, our findings show that organizations at high levels of APDD, that want to make the most of the knowledge diversity of their alliance portfolio, should conduct three specific types of managerial actions, namely mapping the internally available knowledge, scanning the external environment for valuable knowledge, and making forecasts about future technological trajectories and developments. Instead of being overwhelmed by the diversity of cues coming in from their diverse portfolios, managers that help firms to intensively use TM-tools are able to absorb and process these cues, thereby spurring them to higher levels of innovation outcomes.

Besides the contributions of this research, several limitations apply. First, the operationalization of APPD does not allow us to identify individual alliances, but only the existence of alliances with certain types of actors. This approach, which is adopted from the European Community Innovation Survey and has been used in most earlier research on the topic of alliance portfolio diversity as well (Duysters and Lokshin, 2011; Laursen and Salter, 2006), was applied because the data collection problems become exceedingly large when firms are asked about (characteristics of) individual alliances. In order to be able to collect large scale data and, thereby, derive more externally valid results, we chose the research approach discussed in the above sources. Nevertheless, replication with more detailed alliance portfolio data seems a fruitful next step in this kind of research. Moreover, the alliance portfolio construct is clearly a multi-dimensional construct. This study is limited to the partner diversity dimension of the concept. Further research on other dimensions of the construct needs to be done to provide further support of the external validity of the findings reported in this study.

Another limitation lies in the causality claims that can be made on the basis of our analyses. Despite the time lag between the measurements of APPD and a firm's innovation outcomes, our data remains cross-sectional. Without observing changes in one variable being followed in time by changes in another variable, a causal chain is impossible to establish. A similar concern can be voiced 
regarding the role of TM-tools. One could argue that TM-tools simply reflect a fixed ability of firms to transfer innovation inputs to innovation outputs and that they do not reflect time-varying activities that can be directly influenced through managerial action. Even though we have discussed earlier that our data shows that TM-tool use is significantly different from having organizational functions dedicated to TM-activities, observing changes in TM-tool activities over time and relating these to subsequent changes in innovation outcomes is required to provide grounds for causal claims.

Despite these limitations, the main conclusion of this paper, that the role of TM-tools strongly moderates the inverted U-shaped relation between APPD and innovation outcomes, is robust and adds interesting insights to the literatures on alliance portfolios and alliance portfolio management in particular.

\section{Acknowledgements}

The authors would like to thank Will Mitchell, Claudia Schoonhoven, Joseph Lampel, Arjen van Witteloostuijn, Niels Noorderhaven, Bart Nooteboom, Victor Gilsing, Frank Piller and two anonymous reviewers for their valuable comments on earlier versions of this paper. We also are grateful to Bart Hofman and Sanne Keurentjes for their research assistance and to Norman Blight for editing our text. Of course, the usual disclaimers apply.

\section{References}

Bapuji, H., Loree, D., Crossan, M., 2011. Connecting external knowledge usage and firm performance: An empirical analysis. Journal of Engineering and Technology Management 28, 215231.

Barczak, G., Griffin, A., Kahn, K.B., 2009. Perspective: Trends and drivers of success in npd practices: Results of the 2003 PDMA best practices study. Journal of Product Innovation Management 26, 3-23.

Baruch, Y., 1999. Response rate in academic studies: A comparative analysis. Human Relations 52, 421-438. 
Bascle, G., 2008. Controlling for endogeneity with instrumental variables in strategic management research. Strategic Organization 6, 285-327.

Belderbos, R., Carree, M., Lokshin, B., 2006. Complementarity in R\&D cooperation strategies. Review of Industrial Organization 28, 401-426.

Brouwer, E., Kleinknecht, A.H., 1996. Determinants of innovation: A microeconometric analysis of three alternative innovative output indicators, in: Kleinknecht, A.H. (Ed.), Determinants of innovation: The message from new indicators. Macmillan Press, Basingstoke.

Brown, S.L., Eisenhardt, K.M., 1997. The art of continuous change: Linking complexity theory and time-paced evolution in relentlessly shifting organizations. Administrative Science Quarterly 42, 134.

Bruyaka, O., Durand, R., 2012. Sell-off or shut-down? Alliance portfolio diversity and two types of high tech firms' exit. Strategic Organization 10, 7-30.

Cassiman, B., Veugelers, R., 2006. In search of complementarity in innovation strategy: Internal R\&D and external knowledge acquisition. Management Science 52, 68-82.

Cetindamar, D., Phaal, R., Probert, D., 2009. Understanding technology management as a dynamic capability: A framework for technology management activities. Technovation 29, 237-246.

Chen, J., Chen, Y.F., Vanhaverbeke, W., 2011. The influence of scope, depth, and orientation of external technology sources on the innovative performance of Chinese firms. Technovation 31, 362-373.

Cohen, W.M., Levinthal, D.A., 1989. Innovation and learning: The two faces of R\&D. Economic Journal 99, 569-596.

Combs, J.G., Ketchen, D.J., 1999. Explaining interfirm cooperation and performance: Toward a reconciliation of predictions from the resource-based view and organizational economics. Strategic Management Journal 20, 867-888.

Draulans, J., de Man, A.-P., Volberda, H.W., 2003. Building alliance capability: Management techniques for superior alliance performance. Long Range Planning 36, 151-166.

Duysters, G., de Man, A.-P., Wildeman, L., 1999. A network approach to alliance management. European Management Journal 17, 182-187. 
Duysters, G., Lokshin, B., 2011. Determinants of alliance portfolio complexity and its effect on innovative performance of companies. Journal of Product Innovation Management 28, 570-585.

Echambadi, R., Hess, J.D., 2007. Mean-centering does not alleviate collinearity problems in moderated multiple regression models. Marketing Science 26, 438-445.

Faems, D., Van Looy, B., Debackere, K., 2005. Interorganizational collaboration and innovation: Toward a portfolio approach. Journal of Product Innovation Management 22, 238-250.

Feller, J., Parhankagas, A., Smeds, R., 2007. Process learning in alliances developing radical versus incremental innovations: Evidence from the telecommunications industry. Knowledge and Process Management 13, 175-191.

Ford, D., 1988. Develop your technology strategy. Long Range Planning 21, 85-95.

Frishammar, J., Hörte, S.A., 2005. Managing external information in manufacturing firms: The impact on innovation performance. Journal of Product Innovation Management 22, 251-266.

Gnyawali, D.R., Park, B.J., 2011. Co-opetition between giants: Collaboration with competitors for technological innovation. Research Policy 40, 650-663.

Hagedoorn, J., Cloodt, M., 2003. Measuring innovative performance: Is there an advantage in using multiple indicators? Research Policy 32, 1365-1379.

Hall, L.A., Bagchi-Sen, S., 2007. An analysis of firm-level innovation strategies in the US biotechnology industry. Technovation 27, 4-14.

Hernandez-Espallardo, M., Sanchez-Perez, M., Segovia-Lopez, C., 2011. Exploitation- and exploration-based innovations: The role of knowledge in inter-firm relationships with distributors. Technovation 31, 203-215.

Hidalgo, A., Albors, J., 2008. Innovation management techniques and tools: A review from theory and practice. R \& D Management 38, 113-127.

Hoffman, W.H., 2005. How to manage a portfolio of alliances. Long Range Planning 38, 121-143.

Hoffman, W.H., 2007. Strategies for managing a portfolio of alliances. Strategic Management Journal $28,827-856$. 
Isobe, T., Makino, S., Montgomery, D.B., 2000. Resource commitment, entry timing, and market performance of foreign direct investments in emerging economies: The case of Japanese international joint ventures in China. Academy of Management Journal 43, 468-484.

Jiang, R.J., Tao, Q.T., Santoro, M.D., 2010. Alliance portfolio diversity and firm performance. Strategic Management Journal 31, 1136-1144.

Jin, J., von Zedtwitz, M., 2008. Technological capability development in China's mobile phone industry. Technovation $28,327-334$.

Kafouros, M.I., Buckley, P.J., Sharp, J.A., Wang, C.Q., 2008. The role of internationalization in explaining innovation performance. Technovation 28, 63-74.

Kale, P., Dyer, J.H., Singh, H., 2002. Alliance capability, stock market response, and long-term alliance success: The role of the alliance function. Strategic Management Journal 23, 747-767.

Kale, P., Singh, H., 2009. Managing strategic alliances: What do we know now, and where do we go from here? Academy Of Management Perspectives 23, 45-62.

Khalil, T., 2000. Management of technology. The key to competitiveness and wealth creation. McGraw-Hill, Boston.

Kim, J.W., Higgins, M.C., 2007. Where do alliances come from? The effects of upper echelons on alliance formation. Research Policy 36, 499-514.

Koput, K.W., 1997. A chaotic model of innovative search: Some answers, many questions. Organization Science 8, 528-542.

Laursen, K., Salter, A., 2004. Searching high and low: What types of firms use universities as a source of innovation? Research Policy 33, 1201-1215.

Laursen, K., Salter, A., 2006. Open for innovation: The role of openness in explaining innovative performance among U.K. Manufacturing firms. Strategic Management Journal 27, 131-150.

Lavie, D., 2006. The competitive advantage of interconnected firms: An extension of the resourcebased view. Academy of Management Review 31, 638-658.

Lavie, D., 2009. Capturing value from alliance portfolios. Organizational Dynamics 38, 26-36.

Lavie, D., Miller, S.R., 2008. Alliance portfolio internationalization and firm performance. Organization Science 19, 623-646. 
Lee, H., Choi, B., 2003. Knowledge management enablers, processes, and organizational performance: An integrative view and empirical examination. Journal of Management Information Systems 20, $179-228$.

Lettl, C., 2007. User involvement competence for radical innovation. Journal of Engineering and Technology Management 24, 53-75.

Levin, D.Z., Barnard, H., 2008. Technology management routines that matter to technology managers. International Journal of Technology Management 41, 22-37.

Lichtenthaler, U., Lichtenthaler, E., 2004. Alliance functions: Implications of the international multiR\&D-alliance perspective. Technovation 24, 541-552.

Lin, C.H., Wu, Y.J., Chang, C.C., Wang, W.H., Lee, C.Y., 2012. The alliance innovation performance of R\&D alliances-the absorptive capacity perspective. Technovation 32, 282-292.

Miller, D.J., 2004. Firms technological resources and the performance effects of diversification: A longitudinal study. Strategic Management Journal 25, 1097-1119.

Oerlemans, L.A.G., Pretorius, M.W., 2006. Determinants of innovative outcomes of South African firms. An exploratory analysis using firm-level data. South African Journal of Science 102, 589593.

Papalia, R.B., Di Iorio, F., 2001. Alternative error term specification in the log-tobit model, in: Borra, S., Rocci, R., Schader, M., Vichi, M. (Eds.), Advances in classification and data analysis. SpringerVerlag, Heidelberg, pp. 185-192.

Parise, S., Casher, A., 2003. Alliance portfolios: Designing and managing your network of businesspartner relationships. Academy Of Management Executive 17, 25-39.

Phaal, R., Farrukh, C.J.P., Probert, D.R., 2001. Technology management process assessment: A case study. International Journal of Operations \& Production Management 21, 1116-1132.

Phaal, R., Farrukh, C.J.P., Probert, D.R., 2006. Technology management tools: Concept, development and application. Technovation 26, 336-344.

Phelps, C.C., 2010. A longitudinal study of the influence of alliance network structure and composition on firm exploratory innovation. Academy of Management Journal 53, 890-913. 
Riggs, W., Von Hippel, E., 1994. The impact of scientific and commercial value of the sources of scientific instruments innovation. Research Policy 23, 459-469.

Ruef, M., 2002. Strong ties, weak ties and islands: Structural and cultural predictors of organizational innovation. Industrial and Corporate Change 11, 427-449.

Sarkar, M.B., Aulakh, P.S., Madhok, A., 2009. Process capabilities and value generation in alliance portfolios. Organization Science 20, 583-600.

Schilke, O., Goerzen, A., 2010. Alliance management capability: An investigation of the construct and its measurement. Journal of Management 36, 1192-1219.

Sobrero, M., Roberts, E.B., 2002. Strategic management of supplier-manufacturer relations in new product development. Research Policy 31, 159-182.

Tether, B.S., Tajar, A., 2008. Beyond industry-university links: Sourcing knowledge for innovation from consultants, private research organisations and the public science-base. Research Policy 37, 1079-1095.

Toedtling, F., Lehner, P., Kaufmann, A., 2009. Do different types of innovation rely on specific kinds of knowledge interactions? Technovation 29, 59-71.

Utterback, J.M., Abernathy, W.J., 1975. A dynamic model of process and product innovation. Omega 3, 639-656.

Vasudeva, G., Anand, J., 2011. Unpacking absorptive capacity: A study of knowledge utilization from alliance portfolios. Academy of Management Journal 54, 611-623.

von Hippel, E., 2007. Horizontal innovation networks - by and for users. Industrial and Corporate Change 16, 293-315.

Von Raesfeld, A., Geurts, P., Jansen, M., Boshuizen, J., Luttge, R., 2012. Influence of partner diversity on collaborative public R\&D project outcomes: A study of application and commercialization of nanotechnologies in the Netherlands. Technovation 32, 227-233.

Voss, G.B., Sirdeshmukh, D., Voss, Z., 2008. The effects of slack resources and environmental threat on product exploration and exploitation. Academy of Management Journal 51, 147-161.

Wassmer, U., 2010. Alliance portfolios: A review and research agenda. Journal of Management 36, 141-171. 
Wuyts, S., Dutta, S., forthcoming. Benefiting from alliance portfolio diversity: The role of past internal knowledge creation strategy. Journal of Management.

Yamakawa, Y., Yang, H., Lin, Z., 2011. Exploration versus exploitation in alliance portfolio:

Performance implications of organizational, strategic, and environmental fit. Research Policy 40, 287-296. 
Table 1. Non-response analysis

\begin{tabular}{ccccc} 
Variable & Respondents & Non-respondents & Difference & Significance \\
\hline Continuity of R\&D activities & & & & \\
More or less continuously R\&D & $37 \%$ & $40 \%$ & $3 \%$ & $0.46^{\mathrm{a}}$ \\
Occasionally R\&D & $29 \%$ & $29 \%$ & $0 \%$ & $-3 \%$ \\
No R\&D & $34 \%$ & $31 \%$ & & \\
Firms with technological innovations & $54 \%$ & $58 \%$ & $4 \%$ & $0.17^{\mathrm{b}}$ \\
\hline
\end{tabular}

a: Mann-Whitney U-test

b: Phi-test 
Table 2. Descriptive statistics

\begin{tabular}{l|ccccc}
\multicolumn{1}{c|}{ Variable } & Mean & S.D. & Min & Max & VIF \\
\hline \% turnover from incremental innovations & 16.90 & 23.69 & 0 & 100 & n.a. \\
\% turnover from radical innovations & 7.13 & 17.99 & 0 & 100 & n.a. \\
alliance portfolio partner diversity & 0.17 & 0.28 & 0 & 1.00 & 2.19 \\
technology management tools & 2.79 & 3.11 & 0 & 10 & 2.06 \\
use of codified knowledge sources & 0.00 & 1.00 & -0.61 & 4.37 & 1.95 \\
R\&D intensity & 0.04 & 0.09 & 0 & 0.82 & 1.17 \\
innovation bottlenecks & 1.02 & 1.97 & 0 & 9 & 1.25 \\
size (ln) & 4.68 & 1.70 & 0 & 10.31 & 1.31 \\
foreign owned firm & 0.16 & 0.36 & 0 & 1 & 1.04 \\
exporting firm & 0.65 & 0.48 & 0 & 1 & 1.15 \\
firm diversification & 1.34 & 0.75 & 1 & 8 & 1.09 \\
Pavitt sector 2 & 0.27 & 0.44 & 0 & 1 & 1.52 \\
Pavitt sector 3 & 0.13 & 0.33 & 0 & 1 & 1.20 \\
Pavitt sector 4 & 0.16 & 0.37 & 0 & 1 & 1.38 \\
Pavitt sector 5 & 0.28 & 0.45 & 0 & 1 & 1.52
\end{tabular}

n.a. = not applicable 
Table 3. TM-tool use descriptives

\begin{tabular}{r|ccc} 
& \multicolumn{3}{|c}{ Type of TM-tools used } \\
& External & Internal & Technological \\
\hline No TM-tool use & $0 \%$ & $0 \%$ & $0 \%$ \\
Low TM-tool use (1-3 tools) & $79 \%$ & $32 \%$ & $6 \%$ \\
Medium TM-tool use (4-6 tools) & $98 \%$ & $78 \%$ & $30 \%$ \\
Intensive TM-tool use (7-10 tools) & $98 \%$ & $100 \%$ & $97 \%$
\end{tabular}


Table 4. Bivariate correlations ${ }^{\mathrm{a}}$

\begin{tabular}{|c|c|c|c|c|c|c|c|c|c|c|c|c|c|}
\hline & Variable & 1 & 2 & 3 & 4 & 5 & 6 & 7 & 8 & 9 & 10 & 11 & 12 \\
\hline & alliance portfolio partner diversity & - & & & & & & & & & & & \\
\hline 2 & technology management tools & 0.52 & & & & & & & & & & & \\
\hline 3 & use of codified knowledge sources & 0.49 & 0.58 & & & & & & & & & & \\
\hline 4 & $\mathrm{R} \& \mathrm{D}$ intensity & 0.11 & 0.20 & 0.16 & & & & & & & & & \\
\hline 5 & innovation bottlenecks & 0.32 & 0.39 & 0.38 & 0.20 & & & & & & & & \\
\hline & size $(\ln )$ & 0.31 & 0.30 & 0.22 & -0.16 & 0.10 & & & & & & & \\
\hline 7 & foreign owned firm & 0.04 & 0.05 & -0.03 & -0.04 & 0.00 & 0.06 & & & & & & \\
\hline 8 & exporting firm & 0.25 & 0.20 & 0.20 & 0.09 & 0.11 & 0.22 & 0.14 & & & & & \\
\hline 9 & firm diversification & 0.22 & 0.18 & 0.22 & -0.01 & 0.10 & 0.18 & 0.02 & 0.13 & & & & \\
\hline 10 & Pavitt sector 2 & 0.11 & 0.01 & -0.01 & -0.11 & 0.00 & 0.25 & 0.02 & 0.11 & -0.04 & & & \\
\hline & Pavitt sector 3 & 0.16 & 0.13 & 0.15 & 0.12 & 0.10 & 0.14 & 0.00 & 0.18 & 0.04 & 0.26 & & \\
\hline 12 & Pavitt sector 4 & 0.04 & 0.10 & 0.03 & 0.03 & -0.02 & -0.03 & 0.03 & -0.04 & 0.01 & -0.27 & -0.17 & \\
\hline & Pavitt sector 5 & -0.15 & -0.11 & -0.10 & -0.04 & -0.06 & -0.19 & 0.03 & -0.11 & 0.01 & -0.38 & -0.24 & -0.27 \\
\hline
\end{tabular}

a: All correlations larger than $|0.096|$ are significant at $\mathrm{p}<0.05$. 
Table 5. Estimation results

\begin{tabular}{|c|c|c|c|c|c|c|}
\hline \multirow[b]{3}{*}{ Constant } & \multicolumn{3}{|c|}{$\begin{array}{l}\% \text { turnover from incremental } \\
\text { innovations }\end{array}$} & \multicolumn{3}{|c|}{$\%$ turnover from radical innovations } \\
\hline & Model 1 & Model 2 & Model 3 & Model 4 & Model 5 & Model 6 \\
\hline & -0.33 & -0.37 & -0.55 & $-2.29 * *$ & $-2.49 * * *$ & $-3.45 * * *$ \\
\hline alliance portfolio partner diversity (APPD) & - & $14.75^{* * *}$ & $20.72 * * *$ & - & $11.21 * * *$ & $23.16 * * *$ \\
\hline $\mathrm{APPD}^{2}$ & - & $-12.86 * * *$ & $-17.38 * * *$ & - & $-11.07 * * *$ & $-19.32 * * *$ \\
\hline Technology management tools (TM) & - & - & $0.85 * * *$ & - & - & $0.95 * * *$ \\
\hline $\mathrm{TM} * \mathrm{APPD}$ & - & - & $-3.49 * * *$ & - & - & $-4.51 * * *$ \\
\hline $\mathrm{TM} * \mathrm{APPD}^{2}$ & - & - & $2.83 * * *$ & - & - & $3.52 * * *$ \\
\hline use of codified knowledge sources & $1.26 * * *$ & $0.52 * * *$ & $0.36 * * *$ & $1.17 * * *$ & $0.83 * * *$ & $0.73 * * *$ \\
\hline $\mathrm{R} \& \mathrm{D}$ intensity & $3.89 * *$ & $3.47 * *$ & 1.39 & $5.23 * *$ & $5.33 * *$ & $3.99 * *$ \\
\hline innovation bottlenecks & $0.22 * * *$ & 0.08 & $-0.08^{*}$ & $0.31 * * *$ & $0.21 * *$ & 0.04 \\
\hline size $(\ln )$ & $0.14 *$ & 0.07 & $-0.15 * * *$ & -0.12 & -0.15 & $-0.34 * * *$ \\
\hline foreign owned firm & $0.95 * * *$ & $0.71 * *$ & $0.41 *$ & 0.72 & 0.64 & 0.33 \\
\hline exporting firm & 0.20 & -0.12 & 0.02 & 0.67 & 0.54 & 0.72 \\
\hline firm diversification & -0.09 & $-0.26 *$ & -0.11 & 0.08 & -0.06 & 0.16 \\
\hline Pavitt sector 2 & -0.52 & $-0.87 * * *$ & $-0.64 * * *$ & -0.95 & $-1.14 *$ & $-1.00 *$ \\
\hline Pavitt sector 3 & 0.20 & 0.02 & -0.18 & 0.01 & -0.18 & -0.43 \\
\hline Pavitt sector 4 & -0.06 & -0.41 & -0.59 & -0.24 & -0.46 & -0.50 \\
\hline Pavitt sector 5 & -0.42 & -0.29 & -0.52 & -0.87 & -0.78 & -0.99 \\
\hline Number of observations & 419 & 419 & 419 & 419 & 419 & 419 \\
\hline Number of left-censored observations & 202 & 202 & 202 & 303 & 303 & 303 \\
\hline Number of right censored observations & 4 & 4 & 4 & 5 & 5 & 5 \\
\hline Log-likelihood & -616.14 & -569.48 & 455.71 & -421.21 & -413.20 & -382.89 \\
\hline Log-likelihood reduction (sig. based on AIC) & - & $46.44 * * *$ & $113.77 * * *$ & - & $8.01 * * *$ & $30.31 * * *$ \\
\hline Model significance (F-test) & 0.000 & 0.000 & 0.000 & 0.000 & 0.000 & 0.000 \\
\hline Sigma & 2.36 & 2.04 & 1.46 & 3.44 & 3.34 & 2.98 \\
\hline McKelvey \& Zavoina's Pseudo R-square & $36.67 \%$ & $49.03 \%$ & $68.16 \%$ & $19.02 \%$ & $21.14 \%$ & $29.11 \%$ \\
\hline
\end{tabular}

$*: \mathrm{p}<0.10, * *: \mathrm{p}<0.05, * * *: \mathrm{p}<0.01$ (Based on a Huber/White robust specification of standard errors) 


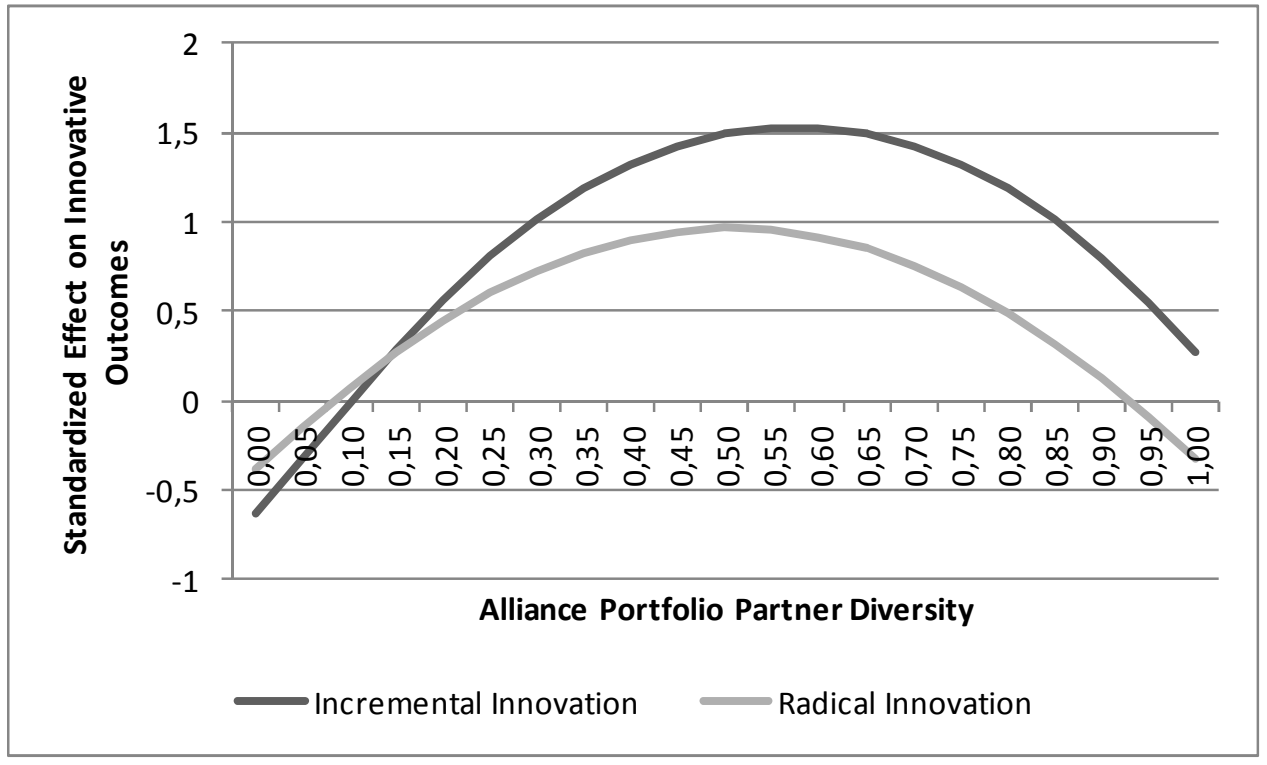

Figure 1. Alliance portfolio partner diversity and innovation outcomes 


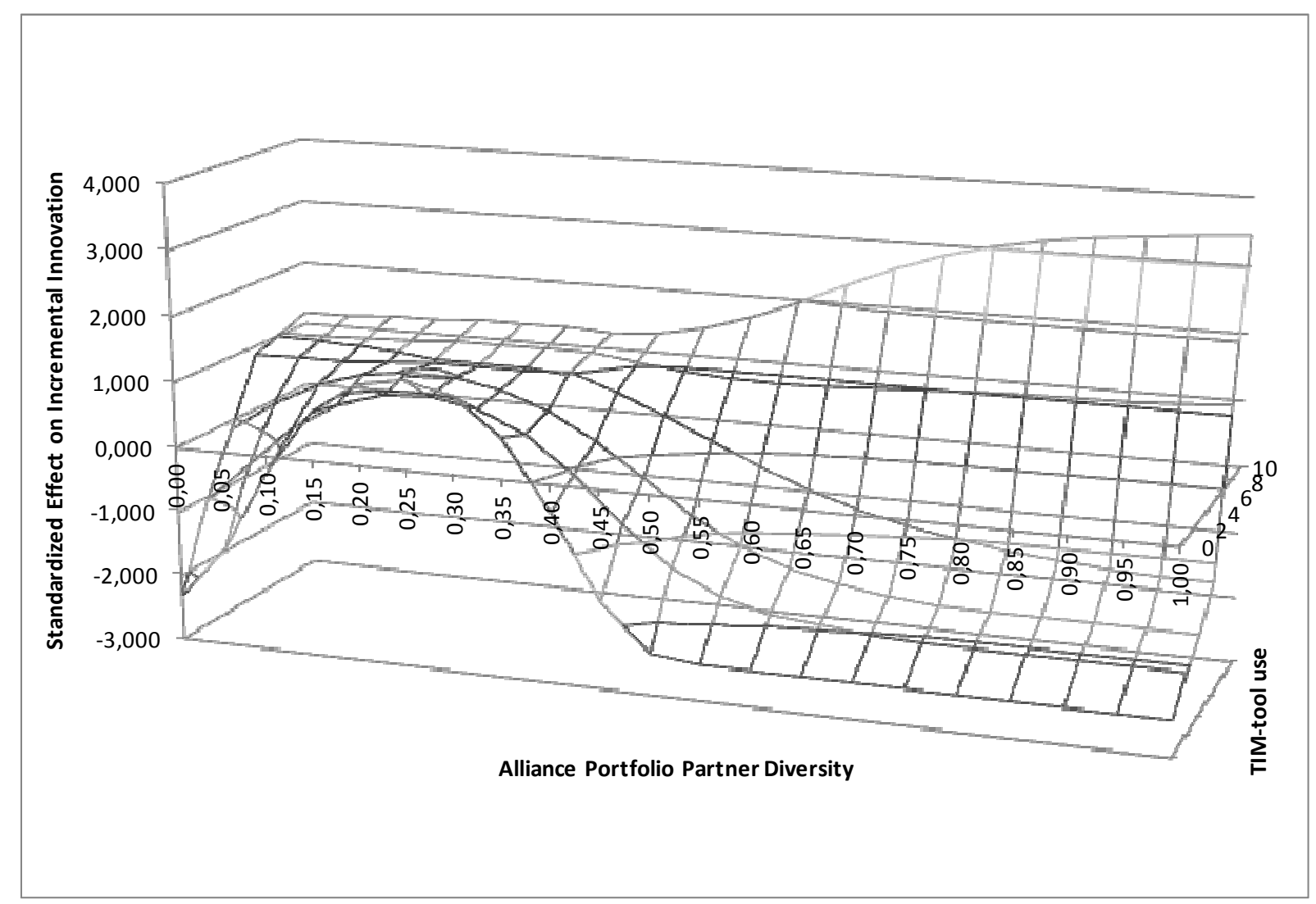

Figure 2a. The moderating effect of TM-tool use on incremental innovative outcomes

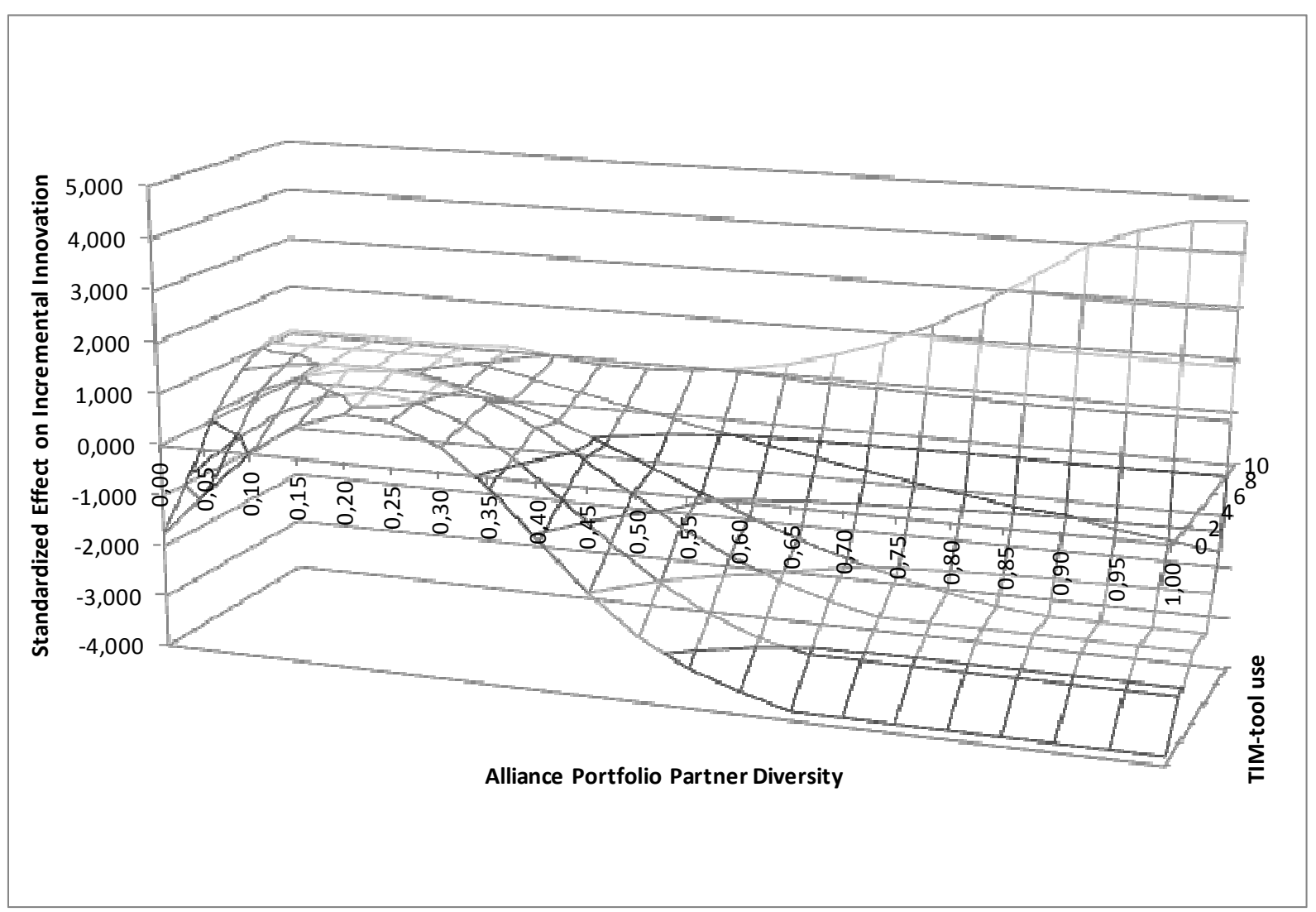

Figure $2 b$. The moderating effect of TM-tool use on radical innovative outcomes 